\title{
ORIGIN OF DEFECTS IN COPPER CONDUCTORS
}

$\mathrm{M}^{\mathrm{r}}$ R. J. E. DEERING contributes a useful article on the origin of defects in copper conductors to the Electrical Review of October 3. When hard drawing became a common practice, copper wire became o practical substitute for galvanized iron wire for overhead telegraph and telephone lines. The effect of the process was to raise the tensile strength of copper from 6.5 tons to 20 tons per square inch, which is almost equal to that of wrought iron, whilst its resistance is only about one-sixth. The effect of the cold drawing of copper is to make its resistivity only. about 3 per cent higher than that of standard annealed copper.

Most contracts for the supply of copper wire quote the British Standards Institution specification, which states that tho wire shall be approximately circular in section, smooth, uniform in quality, pliable, freo from scale, inequalities, 'spills', 'splits' and other defects. Mr. Deering states that representatives of purchasing firms engaged upon the inspection of copper wire may be able to detect physical defects and yet are often unable to detect their origin. The following consideration of the different stages of manufacture will greatly facilitate the tracing of the causes of shortcomings.

During its passage through a succession of rolls nfter it has been ojected at white heat from tho furnace, a copper billet, initially measuring $6 \mathrm{ft}$. by 4 in. by $3 \frac{1}{2}$ in. and weighing $250 \mathrm{lb}$., increases in length as its cross-section diminishes. It emerges from the rolls at a greater linear speed than that at which it entered, for it not only takes up the speed of the rolls, but is also squeezed forward by an amount corresponding to the reduction in crosssectional area. Rapid operation is necessary, as it prevents too great a difference in temperature of tho metal from one end to the other, causing sometimes $1 \frac{1}{2}$ per cent variation in the tensile strength of the wire.

To ensure a reasonable temperature throughout the rod before being drawn into wire, it is 'roughly annealed' by heating at $1200^{\circ} \mathrm{F}$. and quenching with water. It is then pickled in diluto sulphuric acid to remove mill scale. During the rolling, the shape of the cross-section is varied from pass to pass, for if the section were circular throughout fins would be produced; these would bo bent over in the next pass to form 'cold shuts', which might be below the surface for a distance, and possibly remain throughout the complete process. A combination of shapes-squares, ovals and rounds -is therefore used, and this kneads the copper, rendering it homogeneous and ductile.

The next stage is the breaking down of the rod by pulling it through a dieplate with 12-18 holes. The dies are usually of steel, but for copper cast iron is sometimes used. For drawing long lengths of the wire, diamond dies aro occasionally employed. Each hole has two zones-a short tapered one and a bellmoutl leading up to the approach. The walls of the latter must be quite clear of the entering wire, which might otherwise causo the metal of the die to bo drawn forward and piled up in the throat.

A departuro in circularity in section may occur during wire-drawing, if the wire has slipped on the drum of the coiling block, resulting in a 'flat' on the surface through rubbing. Lack of smoothness is sometimes duo to the same cause. Non-uniform quality is traceable to impurities in the ore itself. Absorption of gases giving rise to blowholes when the ore is being smelted into billets may also occur. If during rolling a rod crowds a pass and issues with fins, these may becomo laid into the rod and show up as 'spills' on the surface. These are eliminated by 'scalping'.

The origin of 'splits' occurs in the smelting stage. If a fresh supply of metal is poured into a ladle which already contains a small amount of molten metal, the two will not mix or weld together. The seam or seal so formed will remain throughout the rod or wire being rolled and covered in later stages, so that it may appear on the surface at odd intervals. Two interesting photomicrographs aro shown of a high-conductivity copper rod and of a section of the same rod after it has been made into hard. drawn wire.

\section{BELGIAN EARTHQUAKE OF JUNE II, 1938}

$\mathrm{T}$ HIS earthquake has been studied by 0 . Somville, chief of the Belgian Seismological Service (Annales de l'Observatoire Royal de Belgique, Sério $3,2 ; 1939)$. On June 11,1938 , at midday by the public elocks near the epicentre, an earthquake was felt in Belgium, North France, Holland, NorthWest Germany, Luxembourg and South-East England.

The shock reached intensity VII on Sieberg's modification of the Mercalli-Cancani Scale in central Belgium where it was strongest, and displaced tiles as far away as Herne Bay in England. The earthquake was the most intense of approximately 140 experienced in Belgium since the year 1086. At the Belgian Observatory at Uccle the Wiechert mechanical instruments were thrown completely out of gear, though the long-period Galitzin instruments with galvanometric registration gave the distance as between 50 and 60 kilometres from Uccle and suggested that the epicentre was to the north-west. This latter proved incorrect, as the epicentre by later calculations turned out to be between Audenarde and Renaix, almost west of Uccle. On a basis of 3,570 communications, isoseists were drawn using Sieberg's modification of the Mercalli-Cancani Scale, and two maps showing the 
disposition of these are figured in the text, together with a map showing the point intensities in Holland.

It appears that altogether 17,550 chimneys were damaged, 3,000 in Courtrai alone, which represents 40 per cent of the possible number. There was no loss of life though ten people were slightly injured. Most people heard a sound as of the passage of a heavily laden cart, and several experienced two shocks, of which the second was the stronger. By the method of hyperboles the epicentre was found to be at geographic co.ordinates $50^{\circ} 47^{\prime} \mathrm{N}$., $3^{\circ} 35^{\prime} \mathrm{E}$., with an uncertainty of 4 or $5 \mathrm{~km}$. A diagram of the determination is given in the text. The depth of focus, using the Mohorovicic tables of $\bar{P}-P_{n}$ and
Gutenberg's corrections, was of the order of $45 \mathrm{~km}$., and this was confirmed by the formula for near stations.

$$
\text { Time of propagation of } \vec{P}=\frac{\sqrt{h^{2}+\Delta^{2}}}{V^{r}} \text {, }
$$

where $h$ is depth of focus, $\Delta$ is epicentral distance both in kilometres, and $Y$ is speed of wave taken as $5 \cdot 7 \mathrm{~lm} . / \mathrm{sec}$.

The initial time was calculated to be $10 \mathrm{~h} .57 \mathrm{~m} .42 \mathrm{~s}$. G.IY.T., and it was found that north-east and southwest of the epicentre compression was registered first, whilst in the other two quadrants dilatation was initially experienced. Readings for $P_{n} P^{*} \bar{P} \propto S_{n}$ and $S$ pulses for twenty-four stations in Europe are given together with a graph, and seven of the seismograms are reproduced. Six notable aftershocks have been noted.

\section{SACRED FEASTS OF THE FOX INDIANS}

\begin{abstract}
IN "Ethnography of the Fox Indians" by William Jones, edited by Margaret Welpley Fisher (Bureau Amer. Ethnol., Bull. 125 ; 1939), certain passages are tentatively identified with the contents of a sealed packet recording "ancient mysteries" of the Fox Indians, reported to have been among papers in the custody of the author's father (see NATURE of November 25, p. 914). These passages deal with "The Sacred Feast".

One kind of sacred feast is held in autumn, winter or spring. A man kills a deer and decides to pray. He informs a number of members of his own gens, say, the Eagle gens, of his intention, and each brings food, maple sugar, pumpkin, corn, etc. The prayer is held during the day, beginning in the morning. Waiters come to the lodge of the man getting up the feast and prepare the food; and invitations are then sent to others outside the gens. When the guests appear they find the Eagles waiting for them, seated at one end of the lodge, with the medicine bags spread out in front of them. They drum the air slowly with gourd rattles and ehant songs. Before the first singing and while the food is cooking, the Eagles say to themselves to which spirit the food is sacrificed. The sprinkling of tobacco accompanies the mention of each spirit's name. A period of silence follows, then when the food is cooked the second singing and the eating begin. All food must be eaten before the fourth singing begins, and at the close of the fourth singing all the people disperse.
\end{abstract}

At the summer feasts in the summer bark lodges there is added dancing. As soon as the corn ripens, thanksgiving feasts are held to which each gens invites members of the different gentes. These services are religious, preparatory to the thanksgiving dances. Each gens holds two services at which newly gathered corn is eaten as well as the flesh of a dog killed for the purpose. The inviting gens does not eat, but does the praying to the manitou for his goodness in giving them corn. Theso services are purely religious and no one comes unless invited.

In the same manner in the dances, such as the Wolf or Eagle Feast dances, dog, the principal thing eaten, is an offering made to Nanetowa to invoke his pleasure and presence at the dance, and no one comes to the dance unless he comes with the thought of coming into the presence of Manetowa. There is an atmosphere of sacredness; all enter silently and slowly, and there is no hilarity. During the dancing the men not taking part smoke or chew tobacco, while the women chew but do not smoke. The use of tobacco forms part of the rites to invoke Manetowa.

A feast is often held for the spirit of sickness so that he may not bring sickness. Ho has the power of granting long life. $\mathrm{He}$ is a manitou. Once a Winnebago-among the Winnebago, disease-giver was the most sacred of all their spirits-is said to have had the power of driving away the spirit of sickness. When the people were all dying of smallpox, he rode a white horse painted green and decked out gaily. He would run towards a house, yell at the spirit within, and strike against the lodge. This he did to drive out the spirit, and thereby gained many gifts.

Before a run is made on the buffalo, every camp makes a sacred feast to the buffalo, in which the food must be pumpkin or corn or maple-sugar ; always sugar together with the other two if possible. Dog or any other kind of meat is not used. The feast is made as soon as the hunters know they are in the vicinity of the buffalo.

In the buffalo dance the men and women imitate the run and movement of the buffalo when in flight. The leader in the dance has his head covered by a buffalo mane. Dog, corn and pumpkin are eaten.

The Mowitihagi," "Dirty Little Ant", otherwise known as "Those who worship the spotted calf", is a society in which many of the members belong to the Thunder gens. It is a most important society, ranking with the gentes in some of the buffalo ceremonies. At its dance a small image of a buffalo made of stone is brought out from the bag in which it is usually kept and placed on the floor halfway between two fires. It is about 8-10 inches long and 6-7 inches high, of red stone, and in every respect a representation of a buffalo bull. It is said to be alive and a manitou. In the dance, tobacco is offered to it. It is brought out twice a year only in the sacred feast of the Mowitihagi. 